\title{
Guidelines on the application of the clinical practice guideline on low back pain
}

\author{
Directrices en la aplicación de la guía de práctica clínica en la lumbalgia
}

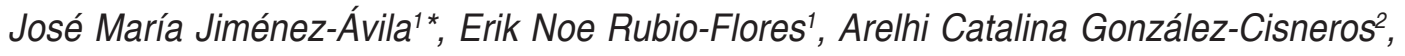
Jaime Eduardo Guzmán-Pantoja ${ }^{1}$ and Elsa Armida Gutiérrez-Román ${ }^{1}$

${ }^{1}$ Centro Médico Nacional de Occidente Hospital, Instituto Mexicano del Seguro Social; ${ }^{2}$ School of Medicine, Instituto Tecnológico de Monterrey. Guadalajara, Jal., Mexico

\begin{abstract}
Introduction: Low back pain is defined as pain in the upper portion of T12 and below the crease of the buttocks and functional limitation. The prevalence of low back pain gradually increases $11.4 \%$ per year. In Mexico, the clinical practice guidelines are not followed in handling low back pain, so it is important to systematize medical care more efficient, since resources are scarce. The first level doctor must meet the benchmarks according to patient need, an incomplete anamnesis is performed, inadequate physical examination, misinterpretation of clinical studies, misdiagnosis, ineffective management, and reference to second or third level not justified. Objective: To provide recommendations for the implementation of syndromic diagnosis, management of adult carriers of low back pain, and correct reference. Implementation of clinical practice guidelines for low back pain syndrome consists of an assessment of the patient by way of "verification", which evaluates certain signs of symptoms, with a total of 37 items for rating, including the sections of clinical symptomatology, AP X-ray, lateral X-ray, sagittal (optional) and axial magnetic resonance imaging (optional), and pain type. Oriented data quickly and easily, from first contact to a syndromic diagnosis in patients with low back pain.
\end{abstract}

KEY WORDS: Guidelines. Low back pain. Application. Spine.

\section{Resumen}

Introducción: La lumbalgia se define como el dolor en el área de la porción superior de T12 e inferior al pliegue de los glúteos, y además limitación funcional. La prevalencia de la lumbalgia va aumentando un $11.4 \%$ por año. En México no se siguen las guías de práctica clínica en el manejo de las lumbalgias, por lo que es importante sistematizar la atención médica para eficientizar, ya que cada vez los recursos son más escasos. El médico de primer nivel debe conocer los criterios de referencia según la necesidad del paciente. Se realizan una anamnesis incompleta, una exploración física inadecuada, una mala interpretación de los estudios de gabinete, un diagnóstico equivocado, un manejo ineficaz y la referencia a segundo o tercer nivel no justificada. Objetivo: Proporcionar recomendaciones para la realización del diagnóstico sindrómico, el manejo de los adultos portadores de lumbalgia y su correcta referencia. La aplicación de las guías de práctica clínica para el síndrome doloroso lumbar consta de una evaluación del paciente a manera de "verificación", en la que se evalúan determinados signos o síntomas, con un total de 37 ítems por calificar, incluyendo los apartados de sintomatología clínica, radiografía anteroposterior, radiografía lateral, resonancia magnética sagital (opcional) y axial (opcional), y tipo de dolor. Estos datos orientan de manera rápida y sencilla, desde el primer contacto, a un diagnóstico sindrómico en el paciente con lumbalgia.

PALABRAS CLAVE: Guías clínicas. Lumbalgia. Aplicación. Columna.

Correspondence:
*José María Jiménez Ávila
Belisario Domínguez No. 1000
Col. Independencia
C.P. 44340, Guadalajara, Jal., México
E-mail: josemajimeneza@ @otmail.com
Date of reception: 23-07-2017

Date of acceptance: 14-02-2018

DOI: 10.24875/CIRUE.M18000004
Cir Cir. 2018;86:24-32

Contents available at PubMed www.cirugiaycirujanos.com 


\section{Introduction}

Low back pain is defined as pain or discomfort in an area around T12 upper portion and inferior to the gluteal fold, together with functional limitation. It should be noted that this definition does not apply to any specific low back pain and is independent of the cause that gave rise to it (Fig. 1).

Low back pain is the second most frequent cause of primary care medical consultation; between 60 and $80 \%$ of the population will experience this problem sometime in their lifetime, which will cause $40 \%$ of all absences from work, reducing the productivity of those affected. The prevalence of this health problem is increasing by $11.4 \%$ per year, and it is therefore a pathology that is seen rather often in health services ${ }^{1}$.

There is a problem that impacts on spinal pathology diagnosis professionalization, since criteria or the so-called clinical practice guidelines (CPG) are not followed in the management of spinal pathology. The diagnosis and treatment of low back pain are complicated by the difficulty in etiology identification and the non-specific nature of pain on many occasions. It is important for medical care to be systematized, since resources are increasingly scant, and it is therefore necessary to make each one of the processes more efficient in addressing the etiology of low back pain.
Some studies have reported that more than $80 \%$ of physicians refer their patients for X-ray studies when there is recurrent back pain, and in more than $70 \%$ when patients present with an episode of low back pain for the first time. Most patients who turn to their family doctor can improve within a couple of weeks, and only a minority will develop chronic back pain. A relationship has been found between body mass index and the prevalence of low back pain ${ }^{2}$, and in very rare cases, serious causes with neurological deficit or neoplasms can be identified.

Analyzing the national panorama and the issuance of sick leaves in some public healthcare institutions, which cover $93 \%$ of the served population, combined they provided 27.8 million days of sick leave in 2007 , which translates into 5.8 billion Mexican pesos ${ }^{3}$.

This reflects the seriousness of the problem, the frequency it occurs with and the cost it causes, which impacts on health expenditure, and when analyzing the pathophysiology of the disease, points of intervention are found in primary care medical attention.

The family doctor is highly responsible for making a rapid and accurate detection, and, if possible, establishing timely medical management since the first contact with the patient with low back pain, as well as to know the appropriate criteria for referral to secondary or tertiary care, according to the patient's real need,

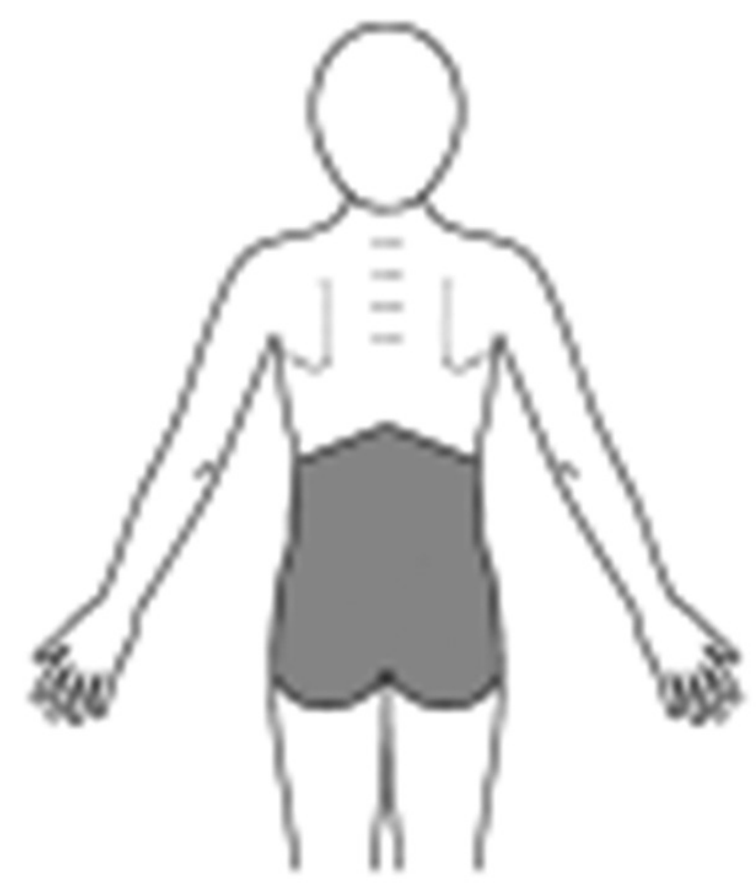

Figure 1. Topographic area regarded as the lower back. 
Table 1. Low back pathologies according to their etiology

\begin{tabular}{llc}
\hline Mechanical & Non-mechanical & Visceral \\
\hline Lumbar strain or sprain: & Neoplasm: & Pelvic organs: \\
- Degenerative disease & - Metastatic carcinoma & - Prostatitis \\
- Discs (spondylosis) & - Multiple myeloma & - Endometritis \\
- Joint surfaces & - Lymphoma and leukemia & - Chronic pelvic inflammatory disease \\
- Diffuse idiopathic hyperostosis & - Tumors of the spinal cord & Kidney disease: \\
Spondylosis & - Retroperitoneal tumors & - Nephrolithiasis \\
Spondylolisthesis & Infection: & - Pyelonephritis \\
Disc hernia & - Osteomyelitis & - Perinephric abscess \\
Spinal stenosis & - Septic discitis & Vascular disease: \\
Osteoporosis with compression fracture & - Paraspinal or epidural abscess & - Aneurysm of the abdominal aorta \\
Fractures & - Endocarditis & - Aortoiliac disease \\
Congenital conditions: & Inflammatory rheumatic diseases: & Gastrointestinal disease: \\
- Severe kyphosis & - Ankylosing spondylitis & - Pancreatitis \\
- Severe scoliosis & - Reiter's syndrome & - Cholecystitis \\
- Paget's disease & - Psoriatic spondylitis & - Intestinal perforation \\
& - Inflammatory bowel disease & \\
\hline
\end{tabular}

since, currently, defective practice by the primary care physician has been going on, who sometimes makes an incomplete history, an inadequate physical examination, incorrect use or bad interpretation of imaging studies, a wrong diagnosis, inefficacious management and unjustified reference to secondary or tertiary care, this despite the existence of CPGs.

It is known that low back pain can be classified, according to its time evolution of, as acute (pain lasts less than 2 to 4 weeks), subacute (pain lasts between 4 and 12 weeks) or chronic (symptoms last more than 12 weeks).

Lower back pain has been classified according to its etiology, overall, in three different types: mechanical, non-mechanical and visceral. The most common are presented in table 1.

All this information is important in order to arrive to an accurate diagnosis, and to achieve this, fundamental propedeutic (introductory) principles must be applied in order for a topographic diagnosis, a syndromic diagnosis and an etiological diagnosis to be established; in addition, if we remember that medicine is not an exact science, we will always have a fourth diagnosis in mind, which will be differential diagnosis.

For this purpose, these guidelines for the application of CPGs are established, whose purpose is to provide the primary care physician with the data, the methodology and the necessary tools to guide him/ her in clinical decisions for patients with low back pain, focusing on accurate diagnosis, specific management and detection of red flags, as well as to know the appropriate criteria for reference to other levels of care and avoid establishing false-positive diagnoses, or, something that can be more serious, false-negative diagnoses.

\section{Objective}

To understand the necessary criteria to define low back pain, with the purpose to diagnose its etiology.

\section{Users}

Family physicians, physical medicine and rehabilitation, traumatology and orthopedics, medical emergencies, general practitioner and all health personnel involved in the primary care of patients with low back pain.

\section{Target population}

Men and women older than 16 years with pain in the lower back region.

\section{Evidence selection}

The search keywords were lumbalgia, lumbago, dolor de la espalda baja (low back pain), dolor de espalda (back pain), atención primer nivel (primary care), GPC (CPG) and guía de práctica clínica (clinical practice guideline), in sources of information dating from 2000 to 2015. The Cochrane Library and Ebsco host research databases were consulted. A review of topics and three review articles were included for the construction of this guidelines. The Medline database was searched and five clinical trials published within the dates of interest were retrieved. 
The localized material was analyzed by the members of the guideline preparation group, and its final inclusion was made by discussion among the participants, using the criteria of the guidelines for medical literature users published in JAMA between 2000 and 2015.

\section{Operational definitions}

- Low back pain: pain or discomfort in the lumbar area, located between the lower edge of the last ribs and the lower crease of the gluteal area, with or without irradiation to one or both legs, and which compromises musculoskeletal and ligament structures, with or without functional limitation that hinders daily life activities and that can cause work absenteeism.

- Nonspecific acute low back pain: this is what is known as "common pain". Its fundamental characteristics are:

- Patient between 20 and 55 years of age.

- Pain in the lumbosacral region, buttocks and thighs.

- Pain of mechanical characteristics.

- Good general condition of the affected individual.

- Chronic back pain: low back pain that occurs for a time period longer than 12 weeks.

- Sciatica: pain radiating towards the back of the leg along the distribution of the sciatic nerve, suggesting mechanical or inflammatory involvement.

- Radiculopathy: dysfunction of a nerve root associated with pain, sensory deficit, cramps or decreased osteotendinous reflexes along the distribution of a specific nerve.

- Lasègue maneuver: clinical test that is carried out with the patient in dorsal decubitus, progressively and slowly flexing the hip of the affected limb, with the knee in extension. It is considered to be positive in case of acute pain irradiating towards the leg in the hip/pelvic flexion between 30 and 60 degrees.

\section{Method}

- Establishment of the topographic diagnosis (low back pain) taking into account the signs and symptoms referred by the patient (adhering to the format on Appendix 1).

- Request for simple X-rays and laboratory tests, trying to identify the type of pain and instability data (Appendix 1).
- Establishment of syndromic diagnosis for referral to a secondary care unit.

- Confirmation of syndromic diagnosis by imaging examination (computerized tomography and magnetic resonance imaging), based on instability and neurological compromise criteria.

- Establishment of etiological diagnosis and identification of signs and symptoms (red flag) for referral to tertiary care unit according to four possible diagnostic actions:

- Traumatic (green color). It causes mechanical pain: it is exacerbated by physical activity and is located in the lumbar area.

- Degenerative (red color). It causes radicular pain: it radiates up to the tip of the big toe, dysesthesias.

- Vertebral destruction syndrome (blue color). It causes nocturnal pain: it increases at night.

- Deformities (orange color). It causes neuropathic pain: by direct injury of a nerve and can affect the limbs.

Once the reason for consultation has been resolved, management will be bidirectional by means of a correct counter-referral, i.e. postoperative patients may be referred from tertiary or secondary care when they require it and, in turn, when they are counter-referred from secondary to primary care for the correct intervention of the primary care physician, allowing the family doctor to function as a stabilizer of medical care of all three levels.

\section{Notes to the algorithm}

\section{Diagnosis}

The primary care physician must carry out a history and physical examination aimed at categorizing the patient with nonspecific low back pain, low back pain potentially associated with radiculopathy or low back pain potentially associated with specific systemic conditions ${ }^{4}$.

\section{Physical examination and classification}

Carrying out an oriented interrogation and physical examination is recommended. Special attention should be paid to patient's age, gender, occupation, time of evolution (acute, $<6$ weeks, subacute, between 6 and 12 weeks, chronic, > 12 weeks) and type of pain (mechanical or inflammatory), and investigate for data of neurological involvement. 
The presence of paresis provides high specificity $(93 \%)$ to the root compression diagnosis, and thus its presence practically confirms the diagnosis ${ }^{5}$.

Urinary retention (sensitivity of $90 \%$ and specificity of $95 \%$ ) and saddle anesthesia are the most useful signs in the diagnosis of cauda equina ${ }^{5}$.

\section{RED FLAG}

Physical examination should be oriented to detect the presence of red flag signs in low back pain:

- Age of onset before 20 or after 55 years of age.

- Recent history of major trauma.

- Constant, progressive, non-mechanical pain (not relieved by rest).

- Pain that worsens at night.

- Chest pain.

- History of malignancies (or suspicion thereof).

- Prolonged use of corticosteroids.

- Abuse of illicit drugs, immunosuppression or infection with human immunodeficiency virus.

- General malaise.

- Unexplained weight loss.

- Structural deformity.

- Fever, recent urinary infection or penetrating wound near the spine.

- Progressive sensory or motor loss.

- History of osteoporosis.

- Lack of improvement after 6 weeks of appropriate conservative management.

- Saddle anesthesia, bilateral sciatica, difficulty urinating or fecal incontinence ${ }^{6}$.

\section{IMAGING STUDIES}

Generally, X-rays of the anteroposterior and lateral lumbar spine are useful in acute low back pain to rule out any occult pathology related to the structural part of the spine.

$X$-ray of the spine is indicated in the patient with low back pain and suspected serious pathology, such as cancer or infection. When signs of alarm are identified in history and physical examination, requesting anteroposterior and lateral projections with the patient in the standing position and without shoes is recommended. On the radiograph, scoliosis, alteration in curvatures, shape of the vertebrae, fractures, listhesis, intervertebral spaces, decrease of the foramen ovale, presence of osteophytes, deference in iliac crests height and soft tissue alterations should be intentionally sought.
Performing imaging tests (X-ray, magnetic resonance and computed tomography) is not recommended in patients with acute low back pain without warning signs ${ }^{7}$.

\section{Pharmacotherapy}

In case of a patient with low back pain without response to treatment after 4-6 weeks of evolution, it is recommended for clinical factors, occupational factors and treatment adherence to be reassessed, as well as performing an intentional search for warning signs and an assessment of the usefulness of imaging studies.

Nonsteroidal anti-inflammatory drugs (NSAIDs) are recommended as first choice in the treatment of acute and subacute non-specific low back pain, due to their better risk/benefit profile. Prior to the start of pharmacological treatment, it is advisable taking into consideration the following aspects: patient age, comorbidity, diet, pharmacological interactions, and cardiovascular and kidney function, as well as the prescription of gastric mucosa protectors in order to prevent complications associated with NSAIDs administration.

In the treatment of chronic low back pain, it is recommended for acetaminophen to be associated a NSAID, with individualized response being assessed in the patient, but the use of NSAIDs for more than 4 weeks is not recommended.

The administration of opioids in acute low back pain is not recommended as initial treatment.

The indication of antidepressants in the management of acute low back pain is not recommended.

There is no evidence that systemic steroids are effective in the treatment of nonspecific low back pain.

Epidural, facet joint, triggering point, or intradiscal infiltrations are not recommended in individuals with subacute or chronic nonspecific back pain.

There is no evidence that vitamin B administration is efficacious for the treatment of nonspecific low back pain?.

\section{Non-PHARMACOLOGICAL TREATMENT}

There is evidence that providing information to the patient with low back pain produces an earlier improvement, reduces the number of doctor appointments and improves the functional status.

Education on the worsening factors, evolution and estimated time for improvement should be provided, which allows to accelerate recovery in patients with 


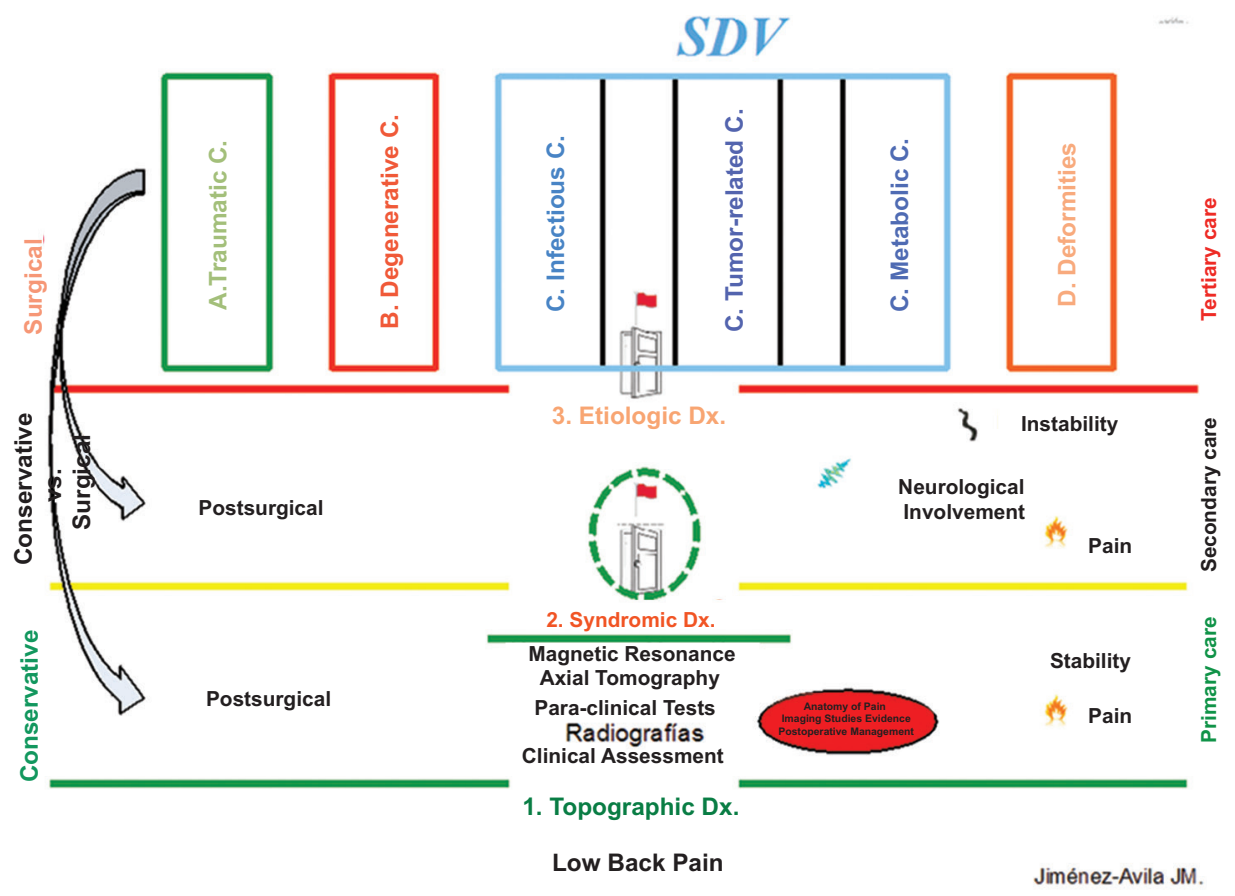

Figure 2. Algorithm for reference and counter-reference of the patient with low back pain.

acute low back pain and to prevent the development of chronic low back pain.

The primary goal of rehabilitation in people with acute low back pain is to try to reduce or eliminate pain, seek re-incorporation into activities and work, prevent deconditioning, disability and the tendency to chronicity, and avoid incorrect and unnecessary behaviors.

There is evidence that patients who maintain an active state and continue with normal activities of daily living, including work, have an earlier symptomatic recovery and reduced disability.

In people with acute low back pain, rest for more than 2-3 days is ineffective and even harmful.

Bed rest is not recommended; if pain intensity requires it, it shall be as short as possible.

Local heat causes a decrease in pain and shortterm disability in acute and subacute low back pain. The application of local cold is not recommended in acute and chronic low back pain.

It is important to recommend the patient to interrupt any activity or exercise that causes an increase in symptoms. Aerobic exercise programs with minimal lumbar effort (walking, bicycle riding, swimming, etc.) can be started within the first 2 weeks in most patients with acute low back pain.

Exercises for the strengthening of trunk muscles, especially the spinal extensors, with gradual increase, can benefit patients with acute low back pain ${ }^{7}$ (Fig. 2).

\section{REFERENCES TO SECONDARY CARE}

- Data consistent with cauda equina syndrome.

- Neurological deficit.

- Inflammatory characteristics, arthritis, acute phase reactants elevation and thoracolumbar or sacroiliac spine radiographic alterations.

- Chronic back pain.

- More than 6 weeks' disability.

- Diagnostic doubt?

\section{SURVEILLANCE AND FOLLOW-UP}

Episodes of pain improve rapidly, but the persistence of residual symptoms is common.

In patients with acute, subacute or chronic low back pain, continuing with daily life activities is recommended, including returning to work as long as pain allows it.

In the patient with acute nonspecific low back, a doctor's appointment is recommended 2-4 weeks after the treatment is instituted, in order to assess treatment response.

Probably effective prevention interventions include physical activity, aerobic exercise, strengthening of the spine extensor muscles and psychosocial factors and job satisfaction assessment? 
Cirugía y Cirujanos. 2018;86

Table 2. Recommendations for returning to work for the patient with acute low back pain

\begin{tabular}{|c|c|c|c|c|}
\hline Level of activity & $\begin{array}{l}\text { Moderate low } \\
\text { back pain }\end{array}$ & $\begin{array}{l}\text { Intense low } \\
\text { back pain }\end{array}$ & Sciatica & Typical modifications \\
\hline $\begin{array}{l}\text { Light work } \\
\text { (seated, standing and lifting up to } 9 \mathrm{~kg} \text { ) }\end{array}$ & 0 days & 0-3 days & 2-5 days & $\begin{array}{l}\text { Not to lift more than } 2.25 \mathrm{~kg} \text { thrice per hour } \\
\text { Not to remain seated, standing or walking without a } \\
5 \text {-minute break every hour }\end{array}$ \\
\hline $\begin{array}{l}\text { Moderate work (standing, walking, } \\
\text { flexing, lifting up to } 22.5 \mathrm{~kg} \text { ) }\end{array}$ & & 14-17 days & 21 days & \\
\hline $\begin{array}{l}\text { Heavy work } \\
\text { (walking, turning, lifting up to } 45 \text { kg) }\end{array}$ & $7-10$ days & 35 days & 35 days & $\begin{array}{l}\text { Not to lift more than } 11.25 \mathrm{~kg} 15 \text { times per hour, } \\
\text { not to remain seated, standing or walking without a } \\
\text { 10-minute break every hour } \\
\text { Driving a car or truck for up to } 6 \text { hours a day, driving } \\
\text { vehicles or using heavy machinery for more than } 4 \\
\text { hours a day }\end{array}$ \\
\hline
\end{tabular}

Times for completely returning to work can vary according to seriousness and type of job, and are those typical for ages from 35 to 55 years. Times for younger workers are

approximately $20-30 \%$ shorter $^{8}$.

\section{SICK LEAVES}

Estimated time for recovery and days of sick leave when appropriate. Prior to determining the days of sick leave in a patient, taking into consideration the following factors that are predictive of chronicity is recommended: previous episodes of low back pain, age $>50$ years, irradiated pain, positive presence of Lasègue's sign, disability caused by pain at the onset of the episode, depression and social isolation or high physical demand at work (Table 2).

Granting a sick leave of more than 2 days to patients with acute nonspecific low back pain is not recommended.

\section{Discussion}

Low back pain is one of the pathologies with the highest incidence in Mexico and Latin America and it is reflected in absenteeism at work. Its syndromic diagnosis includes an important variety of conditions, which range from pain generated by mechanical overexertion to structural pathologies that require surgical management by a highly specialized unit. Therefore, it is highly important for each level of care to clearly know the type of evidence that must be collected in order to establish an efficacious etiological diagnosis and prevent the lengthening of care, or for timely referral in those cases where the low back pathology is associated with problems related to trauma, infections, tumors or metabolic-type disorders, avoiding the establishment of false-positive or false-negative diagnoses.

There are two points that should be highlighted to start the process of care of a patient with low back pain: instability and neurological involvement. These will be the cause of painful symptoms, which are the chief complaint in most patients, and are of utmost importance for decision making from the surgical point of view.

It is necessary to emphasize the relevance of the physical examination initially carried out by the primary care physician, identifying the so-called "red flag" signs, which allow to guide the diagnosis and identify the type of low back pain.

As a final recommendation to strengthen clinical evidence, radiographic evidence should be identified in a targeted manner (Appendix I), since this type of imaging study allows ruling out many injuries that can be treated in the primary or secondary care setting without the need for surgery, which will allow care services to be more efficient by making referrals to the corresponding units.

\section{Conclusion}

The painful low back syndrome is characterized by pain that compromises musculoskeletal and ligament structures. Its etiology is multiple. It can be regarded as being at acute phase when the condition has less than 6 weeks of evolution, and at chronic phase when it goes beyond that period.

The program for CPGs application allows to make efficient the need the Mexican health system has, at the moment that the primary care physician provides care to a patient with a low back pain syndrome. First, the primary care doctor establishes the topographic diagnosis focused on the location of the discomfort the patient attends for. This guideline takes the second step by providing the necessary instruments to 
carry out a syndromic diagnosis. At the same time, it aims to achieve a correct counter-referral in postsurgical patients when they are referred from tertiary to secondary care, and in turn when they are counter-referred from secondary to primary care, for the correct performance of the primary care physician as a stabilizer of medical attention of all three levels of care.

This program has the purpose to enable first-contact medical care to detect the so-called "red flags", which are specific signs or symptoms and that guide to a syndromic diagnosis, and that are presented with a colors guide for easy identification:

- Green color: traumatic.

- Red color: degenerative.

- Blue color: vertebral destruction syndrome.

- Orange color: deformities (neuropathic pain).

Based on the correct identification of clinical signs and radiographic images, as well as on the reinforcement in the updating of family doctors education, improving efficiency in the care of lumbar spine pathology will be possible, by identifying, treating and referring patients in a timely manner to the different levels care, which will shorten waiting times for a specialty appointment and prolonged sick leaves, knocking down indicators that greatly affect the economy of health services.

\section{Ethical responsibilities}

Protection of people and animals. The authors declare that no experiments have been conducted on humans or animals for this research.
Confidentiality of data. The authors declare that no patient data appear in this article.

Right to privacy and informed consent. The authors declare that no patient data appear in this article.

\section{Funding}

No financial support was received in the performance of this study.

\section{Conflict of interests}

The authors declare not having any conflicts of interest with regard to this article.

\section{References}

1. Manchikanti L. CBT for low-back pain in primary care. Lancet. $2010 ; 375$ : 869-70.

2. Smuck M, Kao MC, Brar N, Martinez-Ith A, Choi J, Tomkins-Lane CC. Does physical activity influence the relationship between los back pain and obesity? Spine J. 2014;14:209-16.

3. Covarrubias-Gómez A. Lumbalgia: un problema de salud pública. Revista Mexicana de Anestesiología. 2010;33(Supl 1):5106-9.

4. Chou R, Qaseem A, Snow V, Casey D, Cross JT, Shekelle P, et al. Diagnosis and treatment of low back pain: a joint clinical practice guideline from the American College of Physicians and the American Pain Society. Ann Intern Med. 2007;147(7):478-91.

5. Pérez I, Alcorta I, Aguirre G, Aristegi G, Caso J, Esquisabel R, et al. Guía de Práctica Clínica sobre Lumbalgia Osakidetza. GPC 2007/1. Vitoria-Gasteiz.

6. Cárdenas RU. Dolor lumbar: una aproximación general basada en la evidencia. Univ Med Bogota (Colombia). 2008;49:509-20.

7. Diagnóstico, tratamiento y prevención de la lumbalgia aguda y crónica en el primer nivel de atención. México: Instituto Mexicano del Seguro Social; 2009. Disponible en: http://www.imss.gob.mx/profesionales/ guiasclinicas/gpc.htm

8. Denniston PL, editor. Official disability guidelines. $11^{\text {th }}$ ed. Encinitas, California: Work Loss Data Institute; 2005. 


\section{Appendix}

Appendix 1. Application of the clinical practice guidelines for low-back painful syndrome (checklist).

\begin{tabular}{|c|c|c|c|c|c|}
\hline Clinical Symptoms & Yes & No & & Yes & No \\
\hline Pelvic limbs dysesthesia & & & Brudzinski sign & & \\
\hline Decreased muscle strength & & & Lasègue's sign & & \\
\hline \multirow[t]{2}{*}{ Patellar and Achilles reflex } & & & \multirow{2}{*}{$\begin{array}{l}\text { Patrick's sign } \\
\text { Valsalva sign }\end{array}$} & & \\
\hline & & & & & \\
\hline
\end{tabular}

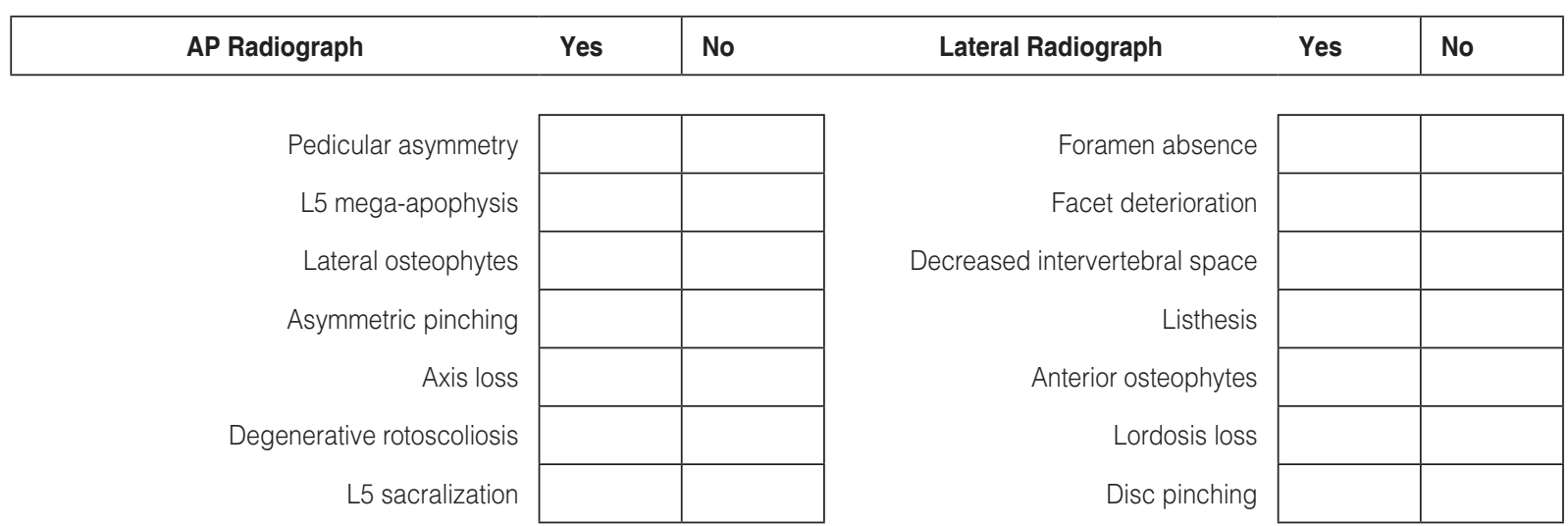

\begin{tabular}{|c|c|c|c|c|c|}
\hline Sagittal MRI (Optional) & Yes & No & Axial MRI (Optional) & Yes & No \\
\hline Degenerative changes & & & Nerve roots compression & & \\
\hline Nerve roots compression & & & Degenerative changes & & \\
\hline Decreased intervertebral space & & & Thickened lamina & & \\
\hline Listhesis & & & \multirow{2}{*}{$\begin{array}{l}\text { Recesses and foramen stenosis } \\
\text { Ligamentum flavum hypertrophy }\end{array}$} & & \\
\hline Disc protrusions & & & & & \\
\hline & & & Facet hypertrophy & & \\
\hline & & & Inter-articular fluid & & \\
\hline
\end{tabular}

\begin{tabular}{|ll|ll|}
\hline Type of Pain & Yes & No & Syndromic Diagnosis \\
\hline
\end{tabular}

\begin{tabular}{r|l|l|}
\cline { 3 - 3 } Radicular Pain & & \\
\cline { 3 - 3 } Mechanical Pain & & \\
\cline { 2 - 3 } Nocturnal Pain & & \\
\cline { 2 - 3 } & &
\end{tabular}

